\title{
The Alignment Analysis Between Classroom Teaching and National Curriculum Criterion-Taking National Quality Class of 2014 as Example
}

\author{
Xiao-yan Zheng ${ }^{1,2}$, Li-mei Ma ${ }^{1}$, Cheng-yin Yang ${ }^{1}$ \\ ${ }^{1}$ School of Chemistry \& Chemical Engineering, Shaanxi Normal University, Xi'an, China \\ ${ }^{2}$ Yinchuan Tanglai Hui Middle School, Yinchuan, China \\ Email address: \\ yangcy@snnu.edu.cn (Cheng-yin Yang)
}

\section{To cite this article:}

Xiao-yan Zheng, Li-mei Ma, Cheng-yin Yang. The Alignment Analysis Between Classroom Teaching and National Curriculum Criterion-Taking National Quality Class of 2014 as Example. Teacher Education and Curriculum Studies. Vol. 2, No. 1, 2017, pp. 1-9. doi: $10.11648 /$ j.tecs.20170201.11

Received: January 9, 2017; Accepted: March 1, 2017; Published: March 22, 2017

\begin{abstract}
Curriculum criterion is the main basis of instructional design. Instructional design can guide classroom teaching activities? Classroom teaching activities can reflect the intention of teaching objectives? With the Achieve alignment analysis tools, this research analyzed the 20 cases of 2014 the National Chemical Quality Course from the centrality, challenge and balance. The alignment of teaching objectives and curriculum objectives in instructional design is not ideal. The presupposition problem's learning level hierarchy of the teaching process is generally higher than the teaching objectives. The number of generative problems is higher than the presuppositions in classroom teaching activities. The generative problem's direction can be expanded around the curriculum objectives and the level hierarchy is essentially flat with the curriculum objectives.
\end{abstract}

Keywords: Chemistry Classroom Teaching, Alignment, Instructional Design, Teaching Objectives, Achieve Analysis Tool

\section{Introduction}

Classroom teaching activities are the main form of teacher implementation of curriculum policy, and national curriculum policy is promulgated in the form of subject curriculum criterions. Does the chemistry classroom activity aligned for the basic requirements of the chemistry curriculum criterions? Aligned to what extent? Researchers use achieve contract analysis tools to analysis the 2014 China Chemical Quality Course Teaching 20cases, questionnaire to conduct a random sample survey of chemistry teachers, and learned the present situation of alignment between classroom teaching of high school chemical teachers and national curriculum criterions, in order to find out the middle school chemistry teachers perform the teaching situation of policy, the chemistry teachers' professional development to provide an empirical basis.

\section{Research Object}

October 2014, observation of national quality classroom of Chemistry in 2014 and teaching reform seminar hosted by
China Education Association Professional Committee of Chemistry in Wuhan. The seminar participants quota allocated by the society, each province 1 contestant. The 31 provinces (municipalities), autonomous region at all levels of society step by step the selection and match points for lessons, scene teaching and effective teaching seminar three parts. There are 31 chemical teachers on behalf of the province to participate in the competition, their level represents the current situation of the development of the middle school chemistry teaching, entries by teachers to prepare in advance. In order to make the research subject more valuable, the study chose 23 contents of high school chemistry compulsory 1 and 2 . Due to three teachers instruction design was missing data. Therefore, for study only 20 knots. The researchers chose 20 festival scene teaching video of the corresponded instruction design. In addition, The Ordinary High School Curriculum Criterion (2003) is the most basic basis, to judgment instruction design and classroom teaching aligned or not according to the curriculum criterions. Therefore, the ordinary high school chemistry curriculum standard is the third research object of 
this research, the researcher referred the introduction and the content criterions in the partial content [1].

\section{Research Tools}

Curriculum alignment mainly studies the matching or appropriateness between the various elements of the curriculum system [2]. Some people have studied the alignment of teaching, learning and assessment in English teaching [3], and some people have studied the alignment of teaching as a symbol of teachers' teaching quality [4]. The ultimate goal of alignment research is to achieve alignment between criterions, teaching materials, teaching and assessment, and to enhance the synergies between these educational elements [5], so that the educational goals can be achieved smoothly. Thus, the states of the United States continue to conduct "research and experimentation between academic assessment and curriculum criterions" [6]. In recent years, the development of alignment tools was relatively perfect, Webb models such as the Webb, N. developed the earliest; Porter, A. to plan curriculum survey of enacted curriculum (SEC) data as the basis to construct the SEC model; Rothman, R. and others [7] on the test with the standard problem made further decomposition and the factors in many aspects, and finally formed three dimensions named centrality, challenge and balance, and a series of indicators of the Achieve framework. Based on the Achieve analysis framework, our study makes an appropriate adjustment to the framework by adapting the localization of the international curriculum consistency research method [8] and combining with the characteristics of chemistry, see Table 1.

Table 1. Classroom teaching and curriculum criterion alignment statistics table.

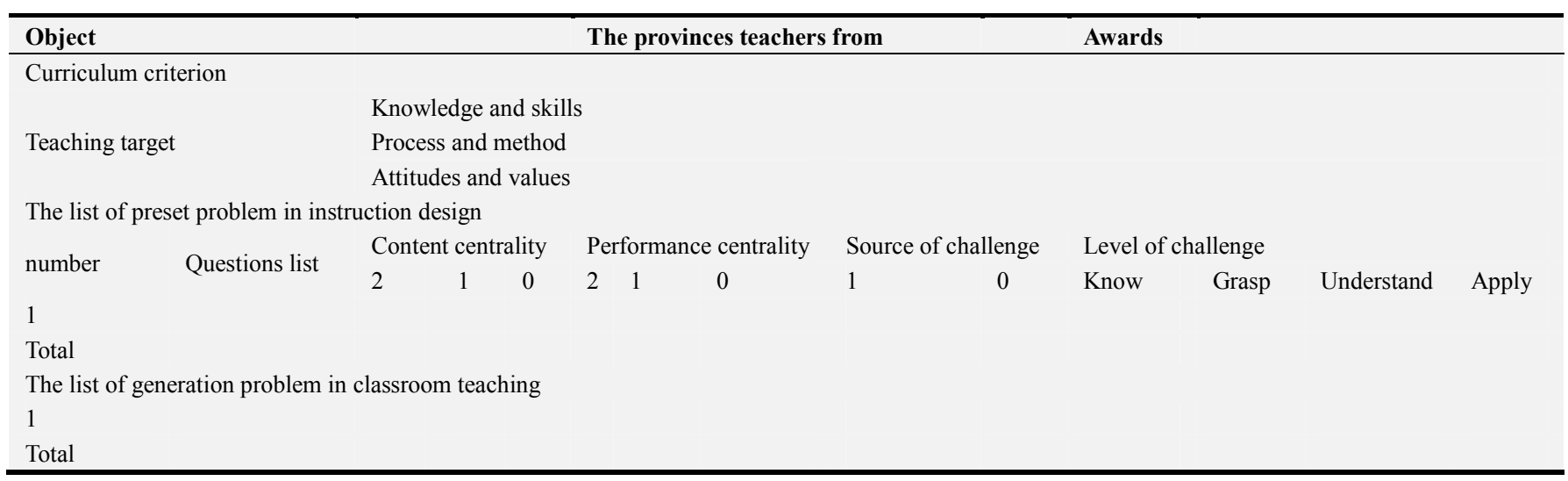

Table 1 refers to the second part of The Ordinary High School Curriculum Criterion (2001), which is based on the third part of the structure. The teaching target is a kind of anticipation to the teaching activity process to consider the curriculum standard [9], the teaching material content structure, the learner development present situation, the teaching condition and the teacher individual characteristic and so on factor.

In the "Content centrality" and "Performance centrality", the grade " 2 " said concerning the subject matter (or cognitive requirements) and curriculum standard in the corresponding learning objectives describe highly correlated; grade " 1 " said issue involves the subject content (or cognitive requirements) and corresponding learning objectives describe roughly related; grade " 0 " said concerning the subject matter (or cognitive requirements) and corresponding learning objectives describe completely irrelevant. In "Source of challenge" index, grade "1" said design appropriate (statement is correct, no technical error); level " 0 " said the design is not appropriate (to describe errors or technical errors). In the "Level of challenge" index, the four levels of "know" "grasp" "understand" "apply" are determined by the level of low to high level of cognitive learning objectives in the chemical curriculum criterions.

\section{Case Analysis Based on Alignment}

\subsection{Instruction Design, Teaching Activity Process and Curriculum Criterion Fit Analysis}

Table 2. The comparison of the preset problems in the instruction design and the generation problems in teaching process in Beijing.

\begin{tabular}{lll}
\hline Object & Methane & $\begin{array}{l}\text { The provinces } \\
\text { teachers from }\end{array}$
\end{tabular}




\begin{tabular}{|c|c|c|c|c|c|c|c|c|c|c|c|c|c|}
\hline \multirow[t]{2}{*}{ Object } & \multirow[t]{2}{*}{ Methane } & \multicolumn{3}{|c|}{$\begin{array}{l}\text { The provinces } \\
\text { teachers from }\end{array}$} & \multicolumn{3}{|c|}{ Beijing } & & \multicolumn{2}{|c|}{ Awards } & \multicolumn{2}{|c|}{ special award } & \\
\hline & & & rienc & he val & ie of & chemical 1 & esea & $\mathrm{h}$ in th & roductio & and life & of human bei & & \\
\hline \multicolumn{14}{|c|}{ The list of generation problem in classroom teaching } \\
\hline \multirow[t]{2}{*}{ Number } & \multirow[t]{2}{*}{ Question list } & \multicolumn{3}{|c|}{ Content centrality } & \multicolumn{2}{|c|}{$\begin{array}{l}\text { Performance } \\
\text { centrality }\end{array}$} & \multicolumn{2}{|c|}{$\begin{array}{l}\text { Source of } \\
\text { challenge }\end{array}$} & \multicolumn{4}{|c|}{ Level of challenge } & \multirow[t]{2}{*}{$\begin{array}{l}\text { class } \\
\text { object }\end{array}$} \\
\hline & & 2 & 1 & 0 & 2 & 10 & 1 & 0 & Know & Grasp & Understand & Apply & \\
\hline 1 & $\begin{array}{l}\text { Methane is suitable for fuel, which } \\
\text { is related to the nature of it? }\end{array}$ & $\sqrt{ }$ & & & & $\sqrt{ }$ & $\sqrt{ }$ & & & $\sqrt{ }$ & & & 3 \\
\hline 2 & $\begin{array}{l}\text { How to explain the stability of } \\
\text { methane with molecular structure? } \\
\text { The spatial arrangement of atoms }\end{array}$ & $\sqrt{ }$ & & & & $\sqrt{ }$ & $\sqrt{ }$ & & & & $\sqrt{ }$ & & 1,3 \\
\hline 3 & $\begin{array}{l}\text { in the molecule of methane } \\
\text { hydrocarbon will not affect its } \\
\text { stability? }\end{array}$ & $\sqrt{ }$ & & & & $\sqrt{ }$ & $\sqrt{ }$ & & & & $\sqrt{ }$ & & 1,3 \\
\hline 4 & $\begin{array}{l}\text { From the point of view of chemical } \\
\text { bond, the bond breaking and bond } \\
\text { in the process of the reaction of } \\
\text { methane and chlorine are analyzed. }\end{array}$ & $\sqrt{ }$ & & & & $\sqrt{ }$ & $\sqrt{ }$ & & & $\sqrt{ }$ & & & 1,2 \\
\hline 5 & $\begin{array}{l}\text { What are the characteristics of the } \\
\text { changes in the molecular structure } \\
\text { of organic compounds in the } \\
\text { process of the generation of } \\
\text { methane? }\end{array}$ & $\sqrt{ }$ & & & & $\sqrt{ }$ & $\sqrt{ }$ & & & $\sqrt{ }$ & & & 2 \\
\hline 6 & $\begin{array}{l}\text { To show the common substitution } \\
\text { reactions in industrial synthesis, } \\
\text { please analyze the substitution } \\
\text { relationship in these reactions. }\end{array}$ & $\sqrt{ }$ & & & & $\sqrt{ }$ & $\sqrt{ }$ & & & & $\sqrt{ }$ & & 4 \\
\hline Total & 6 & 6 & 0 & 0 & 0 & $5 \quad 1$ & 6 & 0 & 0 & 3 & 3 & 0 & \\
\hline \multicolumn{14}{|c|}{ List of questions and statistics generated in the classroom teaching } \\
\hline 1 & $\begin{array}{l}\text { Can you explain why methane is so } \\
\text { electronic? }\end{array}$ & $\sqrt{ }$ & & & $\sqrt{ }$ & & $\sqrt{ }$ & & & & $\sqrt{ }$ & & 1 \\
\hline 2 & $\begin{array}{l}\text { Which students can describe the } \\
\text { distribution of methane molecules } \\
\text { in the normal tetrahedral? }\end{array}$ & $\sqrt{ }$ & & & $\sqrt{ }$ & & $\sqrt{ }$ & & & $\sqrt{ }$ & & & 1 \\
\hline 3 & $\begin{array}{l}\text { Carbon atoms and hydrogen atoms } \\
\text { are connected by what role? }\end{array}$ & $\sqrt{ }$ & & & & $\sqrt{ }$ & $\sqrt{ }$ & & $\sqrt{ }$ & & & & 1 \\
\hline 4 & $\begin{array}{l}\text { Can you use the stick model to } \\
\text { simulate and describe the } \mathrm{CH}_{4} \text { and } \\
\mathrm{Cl}_{2} \text { reaction to reform } \mathrm{CH}_{3} \mathrm{Cl} \text { ? }\end{array}$ & $\sqrt{ }$ & & & $\sqrt{ }$ & & $\sqrt{ }$ & & $\sqrt{ }$ & & & & 2 \\
\hline 5 & $\begin{array}{l}\text { What are the changes in the } \\
\text { molecular structure of the organic } \\
\text { compounds before and after the } \\
\text { reaction? }\end{array}$ & $\sqrt{ }$ & & & & $\sqrt{ }$ & $\sqrt{ }$ & & & $\sqrt{ }$ & & & 2 \\
\hline 6 & Is it just add a $\mathrm{C}-\mathrm{Cl}$ key? & $\sqrt{ }$ & & & $\sqrt{ }$ & & $\sqrt{ }$ & & & & $\sqrt{ }$ & & 2 \\
\hline 7 & $\begin{array}{l}\text { Can you tell the methane into the } \\
\text { process of dichloromethane? }\end{array}$ & $\sqrt{ }$ & & & $\sqrt{ }$ & & $\sqrt{ }$ & & $\sqrt{ }$ & & & & 2 \\
\hline 8 & $\begin{array}{l}\text { what is the process transform } \\
\text { dichloromethane into } \\
\text { trichloromethane? }\end{array}$ & $\sqrt{ }$ & & & $\sqrt{ }$ & & $\sqrt{ }$ & & & $\sqrt{ }$ & & & 2 \\
\hline 9 & $\begin{array}{l}\text { Now can you give a definition of } \\
\text { the substitution reaction? }\end{array}$ & $\sqrt{ }$ & & & & $\sqrt{ }$ & $\sqrt{ }$ & & & & $\sqrt{ }$ & & 2 \\
\hline 10 & $\begin{array}{l}\text { According to the principle of the } \\
\text { reaction between methane and } \\
\text { chlorine, you can predict what } \mathrm{A} \text { is. }\end{array}$ & $\sqrt{ }$ & & & & $\sqrt{ }$ & $\sqrt{ }$ & & & & $\sqrt{ }$ & & 2 \\
\hline 11 & $\begin{array}{l}\text { Judging by the A into a glycine is a } \\
\text { substitute for reaction? }\end{array}$ & $\sqrt{ }$ & & & & $\sqrt{ }$ & $\sqrt{ }$ & & & & $\sqrt{ }$ & & 2 \\
\hline 12 & $\begin{array}{l}\text { Can you explain why you predict } \\
\text { like that? }\end{array}$ & $\sqrt{ }$ & & & & $\sqrt{ }$ & $\sqrt{ }$ & & & & $\sqrt{ }$ & & 2 \\
\hline 13 & $\begin{array}{l}\text { What is the nature of methane } \\
\text { described in the news? }\end{array}$ & $\sqrt{ }$ & & & $\sqrt{ }$ & & $\sqrt{ }$ & & $\sqrt{ }$ & & & & 3 \\
\hline 14 & $\begin{array}{l}\text { Methane can be stable in the } \\
\text { atmosphere, also through } \\
\text { long-distance transport, it reflects } \\
\text { which nature of the methane? }\end{array}$ & $\sqrt{ }$ & & & $\sqrt{ }$ & & $\sqrt{ }$ & & $\sqrt{ }$ & & & & 3 \\
\hline 15 & $\begin{array}{l}\text { Because of the flammability and } \\
\text { stability of the methane, what can } \\
\text { be used to do? }\end{array}$ & $\sqrt{ }$ & & & $\sqrt{ }$ & & $\sqrt{ }$ & & $\sqrt{ }$ & & & & 3 \\
\hline
\end{tabular}




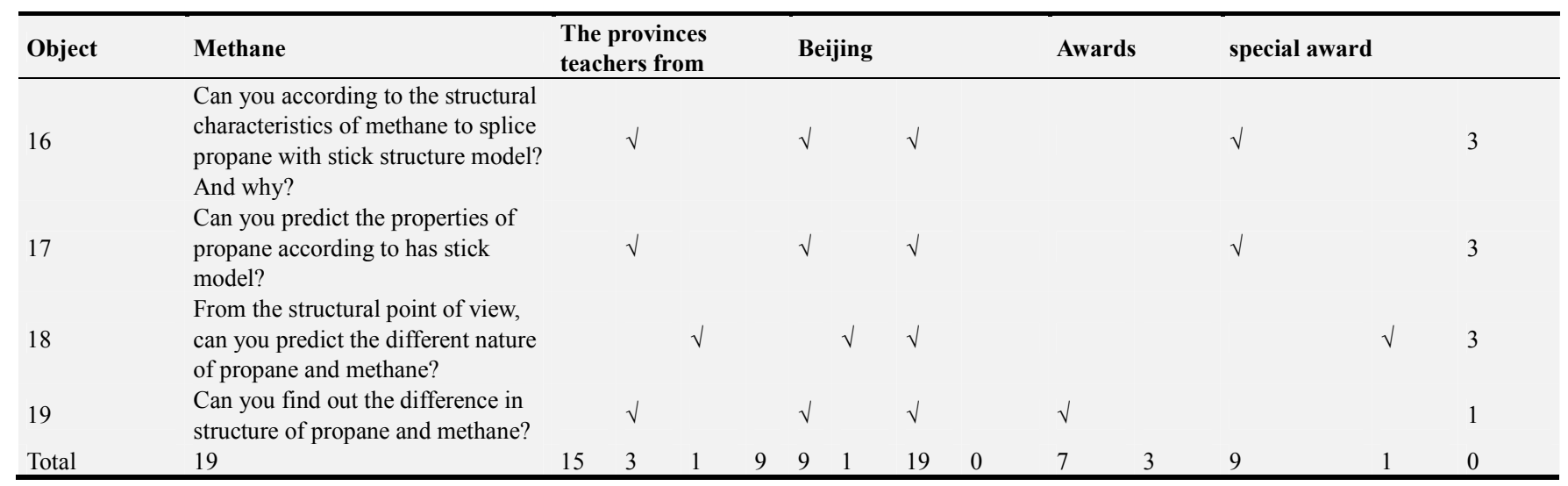

\subsection{The Alignment Analysis Between the Teaching Target Design and the Request of Curriculum Criterion}

In this case, we found two content criterions and one activity and inquiry suggestion, which were designed according to the curriculum criterion. Teachers designed five teaching objectives according to the curriculum criterion, in which "knowledge and skills" designed two content objectives, namely "can say the spatial structure characteristics of methane" and "can from the symbol, micro, macro three levels to describe the methane substitution reaction", from the content point of view, involving the spatial structure of methane and methane, which is alignment with the contents of the curriculum criterions. However, from the point of cognitive learning objectives, the behavior of the two teaching targets are the "name" and "description" are the first levels of cognitive behavior verbs, and the curriculum goal of these two acts verb is "grasp", obviously the teacher's "knowledge and skills" target design level is lower than the target.

\subsection{The Alignment Analysis Between the Teaching Target and the Preset Problems of Teaching Process}

Through statistic the default problem in teacher's instruction design, a total of 6 questions. From the perspective of "centrality", six presupposition in the "Content centrality" were in line with the grade " 2 ", the problem that involves the subject content and the corresponding learning objectives describe exactly the same, this point in the last "class object" statistics has been well reflected. But "Performance centrality" is uneven, most of the question of "Performance centrality" belongs to grade " 1 ", means that the cognitive level of asking and the cognitive level of teaching target set could not be clearly aligned, as shown in the statistics of these six issues to reach the "level of challenge", "grasp" and "understand" level accounted for three, the cognitive level of the problem was obviously higher than the "know" level of the design of instruction target. Finally, from challenging source analysis, these six issues of the "source of challenges" are belong to grade " 1 ". That is to say, without the technical error. In a word, the alignment between the preset problems in teaching process and the teaching target was good in content centrality and the source of challenge, but not that good in performance centrality and the level of challenge.

\subsection{The Alignment Analysis Between the Preset Problems in Instruction Design and the Generation Problems in Teaching Process}

The researchers statistic the generation problem of teaching process, found that the most presented in the form of questions was asking, in this case has 33 questions, but based on some of the questions presented was to draw out the following teaching or to arouse the students' interest, and not to allow students to answer. So the study about the class generated definition for the teacher to ask questions and look forward to students to answer, or is clear that allows the students to answer the questions. After the statistics, the number of questions generated in classroom teaching for 19. And teachers in instruction design only presupposes the six questions, actual is higher than a preset; in the relevance of the content of the problem, the problem of presupposition reflects the high generality and the stage. The problem of classroom generation is more detailed, is often a question of the preset problem corresponds several generation problem in the classroom.

For this 19 questions, we used achieve alignment analysis tools from the two dimensions of "centrality" and "challenge" to carry on the analysis, the following results were obtained. From the "Content centrality" performance of the 19 questions in 15 of the problem was the grade " 2 ", that is, teachers in the classroom proposed 15 questions related to the content and teaching target description alignment, the 3 questions were the grade " 1 ", 1 question was the grade " 0 ". Comprehensive "class target" column of statistical information, all the problems in the classroom generated in the content can be matched with the teaching target. Which has 4 questions correspond with the target 1 , and the 9 questions correspond with the target 2, the 6 questions correspond with the target 3 . From the "Performance centrality" point of view, there are 9 questions in the cognitive level completely alignment on cognitive hierarchy of object design; 9 questions in the cognitive level was not exactly aligned with the cognitive level of the target design. And the cognitive level of the 1 question was completely different from the cognitive level of the target design. Combined with the data statistics of the "level of challenge", the teachers put forward the cognitive 
level of the questions in the classroom were focus on "understand" and "know" levels, and the cognitive level of the teachers' design was "know". Therefore, the cognitive level of the teacher's question was higher than the requirements of the teaching objectives.

\section{20 Case Analysis Based on Alignment}

\subsection{Teaching Targets Design}

Table 3. Quantitative statistics of teaching targets.

\begin{tabular}{|c|c|c|c|c|c|c|c|c|c|c|c|c|c|c|c|c|c|c|c|c|c|c|}
\hline \multirow{2}{*}{$\begin{array}{l}\text { Target dimension } \\
\text { Knowledge and skills }\end{array}$} & \multicolumn{20}{|c|}{ The number of teaching targets in the instruction design } & \multirow{2}{*}{$\begin{array}{l}\text { Total } \\
47\end{array}$} & \multirow{2}{*}{$\begin{array}{l}\text { Average number } \\
2.35\end{array}$} \\
\hline & 2 & 2 & 2 & 4 & 1 & 3 & 2 & 3 & 1 & 3 & 1 & 3 & 3 & 1 & 4 & 2 & 2 & 3 & 1 & 4 & & \\
\hline Process and method & 1 & 3 & 2 & 4 & 3 & 3 & 2 & 2 & 1 & 3 & 1 & 2 & 2 & 1 & 3 & 1 & 2 & 2 & 1 & 4 & 43 & 2.15 \\
\hline Attitudes and values & 2 & 2 & 2 & 2 & 3 & 2 & 2 & 3 & 1 & 3 & 1 & 3 & 5 & 1 & 2 & 2 & 2 & 1 & 1 & 3 & 43 & 2.15 \\
\hline
\end{tabular}

Table 4. Quantitative statistics of the alignment between teaching targets and curriculum criterions.

\begin{tabular}{|c|c|c|c|c|c|c|c|c|c|c|c|c|c|c|c|c|c|c|c|c|c|c|}
\hline \multirow{2}{*}{$\begin{array}{l}\text { Target dimension } \\
\text { Knowledge and skills }\end{array}$} & \multicolumn{20}{|c|}{ Target number of teachers' design goals and curriculum criterions（20) } & \multirow{2}{*}{$\frac{\text { Total }}{30}$} & \multirow{2}{*}{$\begin{array}{l}\text { Average number } \\
1.50\end{array}$} \\
\hline & 0 & 2 & 2 & 4 & 0 & 1 & 1 & 3 & 1 & 1 & 1 & 2 & 3 & 1 & 1 & 0 & 1 & 2 & 0 & 4 & & \\
\hline Process and method & 1 & 1 & 2 & 1 & 1 & 0 & 1 & 2 & 1 & 1 & 1 & 1 & 1 & 1 & 1 & 0 & 1 & 2 & 0 & 2 & 21 & 1.05 \\
\hline Attitudes and values & 2 & 0 & 1 & 1 & 0 & 0 & 1 & 1 & 1 & 0 & 1 & 0 & 5 & 1 & 1 & 0 & 1 & 1 & 0 & 3 & 20 & 1.00 \\
\hline
\end{tabular}

Through statistics the teaching targets of the instruction design of this 20 cases, the number of teaching targets in each dimension was found to be the same, the average of two specific goals, as shown in Table 3. The results show that "knowledge and skills" and the curriculum criterions of the highest, more than 50\%, "process and method" and "emotional attitude and values", are lower than $50 \%$, as shown in Table 4.

\subsection{Instruction Design}

Comparing to the 20 cases, we got the number of the preset problems and the generation problem of the teaching activity process, as shown in table 5.

Table 5. Comparison the number of the preset problem and the generation problem.

\begin{tabular}{|c|c|c|c|c|c|c|c|c|c|c|c|c|c|c|c|c|c|c|c|c|c|}
\hline Statistical item & Qu & tion & uan & & & & & & & & & & & & & & & & & & $\begin{array}{l}\text { Average } \\
\text { number }\end{array}$ \\
\hline preset problem & 6 & 6 & 3 & 5 & 12 & 2 & 13 & 10 & 8 & 0 & 17 & 8 & 17 & 16 & 11 & 7 & 8 & 9 & 0 & 16 & 8.7 \\
\hline $\begin{array}{l}\text { generation } \\
\text { problem }\end{array}$ & 19 & 35 & 25 & 20 & 24 & 30 & 25 & 21 & 19 & 21 & 31 & 15 & 29 & 31 & 21 & 23 & 22 & 22 & 18 & 24 & 23.75 \\
\hline
\end{tabular}

Table 5 data show that the number of preset problems in the instruction design was less, the default content were closely linked with the teaching key, difficulties and key points, some teachers do not set the preset problem. But the researchers analyzed the classroom teaching video found that the frequency of teacher questioning was relatively high. Table 5 data show that the number of generation problem was 2 to 2.5 times as much as the number of preset problem.

Although the preset problem was far less than the generation problem. However, the preset problem in teaching practice can be found, but not useless. The reason why there are many problems in the practical teaching, on the one hand, may be the teacher in order to emphasize and put forward the problem to set aside time, also may be in order to test the students' target.

In short, the generation problem and the preset problem does not have a precise alignment, but it was not completely non alignment, belong to the fuzzy aligned.

\subsection{The Alignment Analysis Between the Preset Problems and Teaching Objectives}

The alignment between the preset problems and the teaching targets in the instruction design, the researchers used achieve alignment analysis tools from "level of challenge", "Content centrality", "Performance centrality" and "source of challenge" four angles to analyze. The average performance level of 20 teaching cases in each index is shown in Table 6.

Table 6. The average performance level of "centrality" and "challenge" of preset problems in instruction design.

\begin{tabular}{|c|c|c|c|c|c|c|c|c|c|c|c|c|}
\hline \multirow[t]{2}{*}{ Object } & \multicolumn{4}{|c|}{ Level of challenge } & \multicolumn{3}{|c|}{ Content centrality } & \multicolumn{3}{|c|}{ Performance centrality } & \multicolumn{2}{|c|}{ Source of challenge } \\
\hline & Know & Grasp & Understand & Apply & g"2" & g"1" & g"0" & g"2" & g"1" & g"0" & g"1" & g"0" \\
\hline Ratio & 0.25 & 0.41 & 0.30 & 0.04 & 0.98 & 0.02 & 0.00 & 0.48 & 0.29 & 0.23 & 1.00 & 0.00 \\
\hline
\end{tabular}




\subsubsection{Level of Challenge}
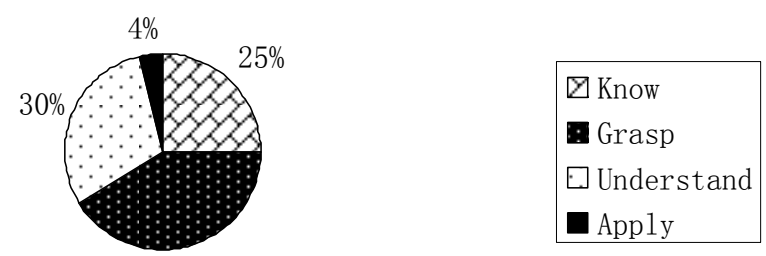

$41 \%$

Figure 1. The level of challenge of instruction design preset problems distribution ratios.

From the level of challenge, in the selection of the 20 cases, except two cases of instructional design without any problem of default, the remaining 18 cases have the preset problem.
Compare the cognitive level of teacher's preset problem with the 4 cognitive learning objectives about the content standard of curriculum standard, and then carry on the division of cognitive level. In each case, the ratio of the number of different cognitive levels is calculated. Finally, calculate average value of 18 cases which has same cognitive level, the data shown in Figure 1. The results show that most of the cognitive level of the teachers' presupposition focus on the level of "grasp", the second was "understand", the third is "know", "apply" level is the least, only $4 \%$.

We statistics on the action verbs used in the 6 subject of the contents standard of the compulsory 1 and 2 in the standard of chemistry curriculum criterions of senior high school, and then classified statistics according to the cognitive level, the results are shown in Table 7.

Table 7. The compulsory 1 and compulsory 2 content standards use of cognitive behavior verb.

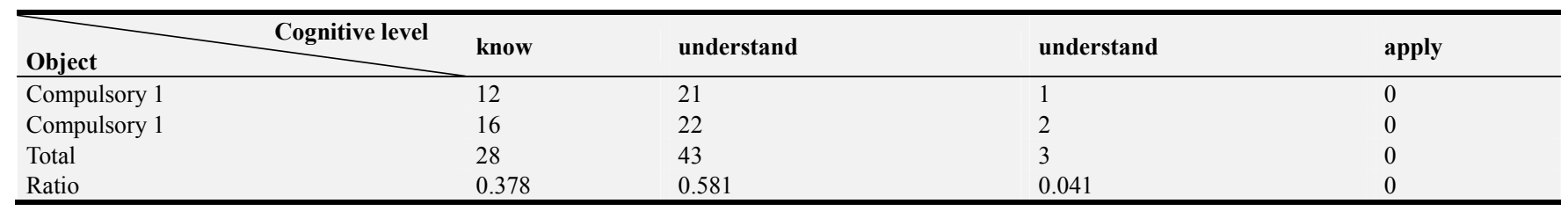

From table 7 statistical data we can see that compulsory 1 and 2 in the course standard of description of the contents standards used by the behavior verbs of the cognitive level were mainly concentrated in the "understand" level, the ratio was close to $60 \%$, "know" level, accounting for $37.8 \%$. And the level of "grasp" is $4 \%$, the cognitive level of "apply" in the compulsory 1 and 2 of the content standards are not reflected.

Compared the cognitive level of the behavior verbs used in compulsory 1 and 2 of the course standard and the average level of the 20 cases in the "level of challenge" index, which was the highest in the level of "grasp" and the proportion of "apply" was the lowest, and the ratio of "know" level shows that the course standard was higher than the proportion of the teacher's default. It shows that the teacher makes the number of the level to be reduced by raising the asking of "knowing" the level of cognition in the classroom. This process may be the students generally can easy to master on the knowledge of this cognitive level, more easily. For the level of "grasp", it shows that the proportion of presupposition was much higher than that of the course standard, and the teachers pay more attention to the knowledge of "grasp" level in the classroom. On the other hand, because of the curriculum criterions has many targets on the level of "grasp", and the teachers in the classroom may be promote the target requirements of less than the "grasp" level, lead to the proportion of the "grasp" level in the preset problems increase more. In short, the distribution of 4 cognitive levels was basically in alignment with the theory and practice.

\subsubsection{Performance Centrality}

The cognitive level of the preset problem in the teaching process is compared with the cognitive level of the teaching target. If the preset problem is the same as the level of teaching target, it is divided into grade " 2 "; if the cognitive level of the preset problem is higher than the cognitive level of the teaching target, it is divided into grade " 1 ". If the cognitive level of the preset problem is lower than the cognitive level of the teaching target, it is classified into grade "1", see Figure 2.
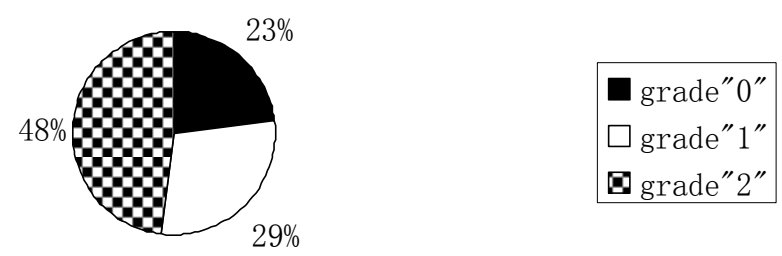

Figure 2. The performance centrality of the instruction design preset problems distribution ratios.

Figure 2 shows that 18 cases (there are two cases no design questions, therefore, only 18 cases) in the performance centrality of the teachers preset problems is grade " 2 " to $48 \%$, that is, the $48 \%$ cognitive level of preset problems and the cognitive level of the teaching target are fully aligned; there are $29 \%$ cognitive level of preset problems and the cognitive level of the teaching target are fuzzy aligned; $23 \%$ the cognitive level of the preset problems are not aligned for the cognitive level of the teaching target.

\subsubsection{Content Centrality}

Compared with the performance centrality, the content centrality showed a high consistency. The $98 \%$ contents of the preset problems and the content of the teaching target are fully aligned, belonging to grade " 2 "; the $2 \%$ contents of the preset problems and the content of the teaching target grade is " 1 ", are fuzzy aligned. Teachers use these questions for in order to elicit the contents of this section and put forward the question of lower correlated, see Figure 3. 


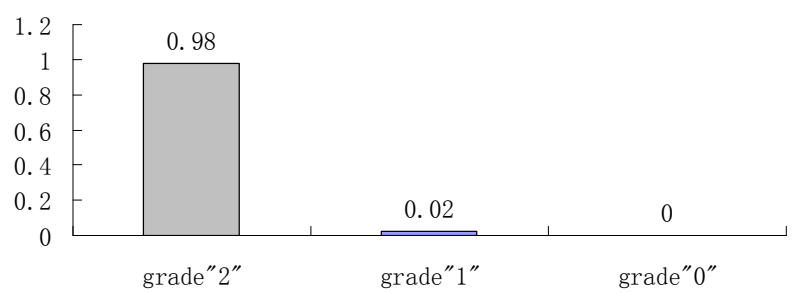

Figure 3. The content centrality of the instruction design preset problems distribution ratios.

\subsubsection{The Source of Challenge}

In the select cases, in each case the source of challenge is belong to grade " 1 ". That is, there is no technical error in the question of the teacher's default, this may be related to the special nature of the case. After all, it is a national contest, and the team will be very careful with the instruction design.

\subsection{The Alignment Analysis Between the Teaching Activities and the Teaching Objectives}

According to the processing method of the preset problems, the researcher makes a statistic on the questions raised by the teachers in the classroom teaching by observing the teaching video, and then use the Achieve alignment analysis tool to evaluate. Get the result that the 20 teaching cases respectively in the level of challenge, content centrality, performance centrality, source of challenge index average data as shown in table 8 shows.

Table 8. 20 instruction design generation problems' average performance level of "centrality" and "challenging”.

\begin{tabular}{|c|c|c|c|c|c|c|c|c|c|c|c|c|}
\hline \multirow[b]{2}{*}{ Item } & \multicolumn{4}{|c|}{ level of challenge } & \multicolumn{3}{|c|}{ content centrality } & \multicolumn{3}{|c|}{ performance centrality } & \multicolumn{2}{|c|}{ source of challenge } \\
\hline & $\mathrm{K}$ & $\mathrm{U}$ & $\mathrm{C}$ & $\mathrm{A}$ & g"2" & g"1" & g"0" & g"2" & g"1" & g"0" & g"1" & g"0" \\
\hline Ratio & 0.28 & 0.39 & 0.29 & 0.04 & 0.91 & 0.08 & 0.01 & 0.44 & 0.30 & 0.26 & 1.00 & 0.00 \\
\hline
\end{tabular}

\subsubsection{Level of Challenge}

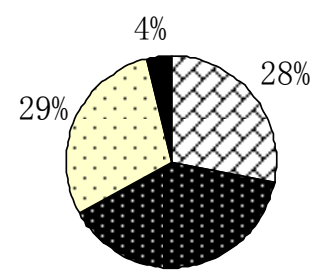

$39 \%$

Figure 4. Level of challenge of the generation problems distribution ratios.

Figure 4 shows that teachers in the classroom teaching of the cognitive level of generation problems are mainly concentrated in the "grasp" level, the questions of "know" and "understand" level are take second place. the "apply" level of the questions are the least. This is in alignment with the cognitive level of the teachers' preset problems, the level of "understand" is the highest, "understand" and "know" after, but the number of questions in "understand" level is a little higher than the "know" level.

\subsubsection{Performance Centrality}
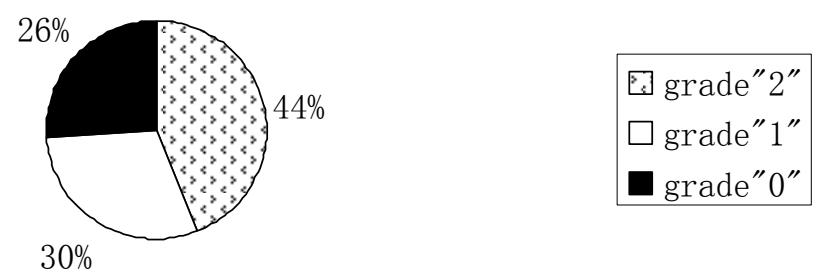

Figure 5. Performance centrality of the generation problems distribution ratios.

The level of "performance centrality" of generation problems and preset problems in classroom teaching are similar, the ratio of grade " 2 " is higher than grade" 1 " and grade " 0 ", data show that the cognitive level of the generation problems and the cognitive level of the teaching target accurately align ratio accounted for $44 \%$, the ratio of fuzzy aligned is followed, accounting for $30 \%$, the ratio of completely non aligned to $26 \%$.

\subsubsection{Content Centrality}

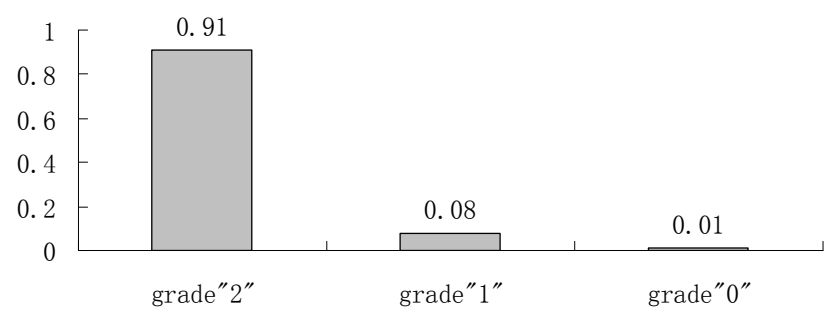

Figure 6. Content centrality of the generation problems distribution ratios.

In the classroom teaching, the content centrality of the generation problems is better, the ratio of grade " 2 " accounted for $91 \%$, namely, the knowledge content of generation problems and the content of the teaching target demand to achieve a precise alignment to the ratio of $91 \%$. Can be seen, whether it is the content centrality of the preset problems or the generation problems are showing a high alignment

\subsubsection{The Source of Challenge}

In the classroom teaching, teachers are often due to the influence of variable factors, appear the technical errors, but the positive is that in the 20 cases investigated, these teachers in such a large-scale competition in the field of teaching activities, there is no technical error in asking questions, showing a strong teaching ability.

\section{Conclusions}

Research Conclusions

First, the teaching objectives design and the national chemistry curriculum criterions of the alignment in general in the 20 case. In teaching practice, the process of teaching 
activities should be closely around the teaching objectives of the implementation of teaching [10], any dislocation of teaching objectives will lead to the imbalance of teaching activities, making teaching effectiveness becomes lower. Data show that the alignment of teaching objectives and curriculum objectives is not good. The reason of generally alignment mainly has the following two points: first, teachers is not clear that who is the target behavior subject of teaching objective design, "knowledge and skills" goal of the subject is still relatively clear, but some design appear "enable students to master". However, the target behavior subject of "process and method" and "emotional attitude and values", which confused us more. A lot of teachers describe as "let students" "make students" "to cultivate students" and so on, which will be the behavioral subject of learners become teachers. Secondly, the cognition about the explicit behavior of the cognitive target and the behavior verbs of experiential target implicit in the perception is not clear, often use ambiguous verbs to describe, and some teachers are not clear about the cognitive level of the verb, so the goal is to make a comparison. Especially the use of behavior verbs about the "process and method" and "emotional attitude and value" exist many problem. In such a high level of national competition appear such problems, it can not simply be attributed to the quality of teachers is not high, more should be reflected from the curriculum criterions of the formulation and expression.

Second, the alignment between the questions in instruction design and teaching objectives. The preset problems in instruction design is very good in "Content centrality", is general in "Performance centrality", appear that the "level of challenge" of the preset problems is higher than the teaching objectives of cognitive level requirements. For example, increase the number of questions about "understand" levels, the number of "know" is reduced. The ninth questions of the questionnaire survey show that more than $80 \%$ of the teachers think that the main purpose of the questions in instruction design is to check the implementation of the teaching objectives. Seventh questions shows that more than $65 \%$ of the teachers presupposition is based on the teaching objectives. It can be seen that most of the teachers can realize that the preset problems should be aligned with the teaching objective, rather than random questions.

Third, the alignment between generation problems in teaching and teaching objectives. The number of questions generated by the teacher in the classroom teaching is much higher than the number of questions in instruction design. Compared to the preset problems, it has a greater randomness, so the alignment between the generation problems and the teaching objectives can reflect the whole situation of the chemistry classroom teaching in the whole country. Through the analysis of the 20 cases, the results show that the generation problems is very good about "Content centrality", the "level of challenge" level as same as the preset problems'.

Fourth, the alignment between generation problems and preset problems. The number of generation problems in practical teaching is far more than the number of the default.

In a word, the researchers found that the alignment between classroom teaching of Chinese high school chemistry and national curriculum criterions was good, after the study of these chemical teachers. The main reason may lie in from the teaching objectives to the national curriculum criterions did not do a good aligning, which leads to the later alignment of the confusion. Further survey shows that nearly half of the chemical teachers can not do accurate description of three-dimensional teaching objectives, the specific performance of the behavior of the main confusion, the use of behavior verbs are not accurate, can not choose the experiential learning objectives on different levels of behavior verbs. As the teaching objective is not aligning to the national curriculum criterions, the deviation should be produced when the preset problems and the generation problems is relative to the teaching target.

Teaching Suggestions

Based on the above conclusions, the researcher puts forward the following suggestions, hoping to improve the quality of teaching in the chemistry classroom.

First, the instruction goal design is the planning of the expected results of teaching activities [11]. In view of the problems that arise in the design of teachers' teaching objectives, we should strengthen teachers' grasp and learning of curriculum criterions, and standardize the writing of teaching objective design.

Second, teachers should pay more attention to the efficiency of classroom questions, presuppose the key issues to be raised in the classroom [12], establish the linkages between the problems and progressive progress, and make full use of the feedback effect of the questions to evaluate the achievement of the three-dimensional teaching objectives.

Third, to improve the importance of chemistry teachers in the classroom teaching should be align with the national curriculum criterions. Real implement the curriculum reform based on curriculum criterions.

Fourth, refine the chemistry course standard to every chemical teacher can operate such a level, in particular, some of the key terms should be defined as operational definitions, and take some examples. Increasing the investment of training funds, so that every chemical teacher can understand the curriculum criterions, instruction design, teaching activities between the principles of the alignment, promote students' scientific literacy, and promote the professional development of teachers, so that they are in a virtuous circle.

\section{Acknowledgments}

This thesis is a key project of education reform in Higher Education in Shaanxi Province in 2015: based on the concept of cooperative education for "the construction of excellent teacher training system", it is the stage achievement [2015] 21 of higher education in Shaanxi Province. It is supported by the research project of Teachers' Education of Shaanxi Normal University which is about the construction of the curriculum system aiming at cultivating outstanding teachers of science. No. JSJY2015J009. 


\section{References}

[1] The Ministry of Education of the People's Republic of China. Chemistry Curriculum Criterion of Ordinary Senior High School [S]. Beijing: People's Education Press, 2003:5-6, 9-13.

[2] Dai-ping Duan, Guang-zhou Li \& Juan Ni. Curriculum Aligning: Method Comparison, Problem Reflection and Localization [J]. Journal of The Chinese Society of Education, 2015, (06): 73-78.

[3] Marina Burger. The Alignment of Teaching, Learning and Assessment in English Home Language in Grade 10 in District 9, Johannesburg [D]. University of South Africa, 2008.

[4] Morgan S. Polikoff, Andrew C. Porter. Instructional Alignment as a Measure of Teaching Quality [J]. Educational Evaluation and Policy Analysis, 2014, 36(4): 399-416.

[5] Yu-qin Yang, Zu-hao Wang \& Xin-yu Zhang. Evolution and Implications of American Curriculum Alignment Research [J]. Foreign Educational Research, 2012, (01): 113-121.

[6] Lei Zhang. Academic Evaluation and Curriculum Criterions Alignment Analysis Model and Case Study [D]. Northeast Normal University, 2011.

[7] Yu-qin Yang, Xin-yu Zhang \& Xiao-hong Zhan. The United States of Achieve "Test - Standard" Analysis of the Alignment of the Tool of Research and Revelation [J]. Primary \& Secondary Schooling Abroad, 2011 (9): 22-27.

[8] Dai-ping Duan. High School Chemistry curricular Alignment Research [D]. Nanjing Normal University, 2015.

[9] Zhi-xin Liu. Chemistry Teaching Theory [M]. Fourth Edition. Beijing: Higher Education Press, 2009: 114.

[10] Zheng-xiang Zhou, Jia-gen Yang. Chemistry classroom teaching return to the true [J]. Journal of Shanxi Normal University (SOCIAL SCIENCE EDITION), 2014, (S5): 303-304.

[11] Cheng-yin Yang. Chemistry Curriculum and Teaching Theory [M]. Xi'an: Shaanxi Normal University Press, 2010:115.

[12] Cheng-yin Yang. Chemistry Instructional Design and Skill Practice [M]. Beijing: Science Press, 2007: 168. 